\title{
BMJ Open Objectively measured physical activity in Finnish employees: a cross-sectional study
}

\author{
Sara Mutikainen, ${ }^{1}$ Elina Helander, ${ }^{2}$ Julia Pietilä, ${ }^{2}$ Ilkka Korhonen, ${ }^{2,3}$ Urho M Kujala ${ }^{1}$
}

To cite: Mutikainen S, Helander E, Pietilä J, et al. Objectively measured physical activity in Finnish employees: a cross-sectional study. BMJ Open 2014;4: e005927. doi:10.1136/ bmjopen-2014-005927

- Prepublication history for this paper is available online. To view these files please visit the journal online (http://dx.doi.org/10.1136/ bmjopen-2014-005927).

Received 17 June 2014 Revised 2 October 2014 Accepted 30 October 2014

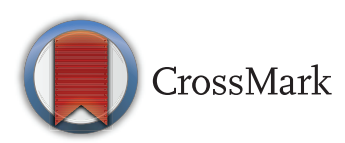

\footnotetext{
${ }^{1}$ Department of Health Sciences, University of Jyväskylä, Jyväskylä, Finland ${ }^{2}$ Department of Signal Processing, Tampere University of Technology, Tampere, Finland

${ }^{3}$ VTT Technical Research Center of Finland, Tampere, Finland
}

Correspondence to Professor Urho M Kujala; urho.m.kujala@jyu.fi

\section{ABSTRACT}

Objectives: To objectively measure the amount of intensity-specific physical activity by gender and age with respect to body mass index (BMI) during workdays and days off among Finnish employees.

Design: A cross-sectional study.

Setting: Primary care occupational healthcare units. Participants: A sample of 9554 Finnish employees (4221 men and 5333 women; age range 18-65 years; BMI range $18.5-40 \mathrm{~kg} / \mathrm{m}^{2}$ ) who participated in health assessments related to occupational health promotion. Main outcome measurements: The amount of moderate-to-vigorous (MVPA) and vigorous (VPA) physical activity ( $\geq 3$ and $\geq 6$ metabolic equivalents, respectively) was assessed by estimating the minuteto-minute oxygen consumption from the recorded beat-to-beat R-R interval data. The estimation method used heart rate, respiration rate and on/off response information from R-R interval data calibrated by age, gender, height, weight and self-reported physical activity class. The proportion of participants fulfilling the aerobic physical activity recommendation of $\geq 150 \mathrm{~min} /$ week was calculated on the basis of $\geq 10$ min bouts, by multiplying the VPA minutes by 2 . Results: Both MVPA and VPA were higher among men and during days off, and decreased with increasing age and BMI ( $p<0.001$ for all). Similar results were observed when the probability of having a bout of MVPA or VPA lasting continuously for $\geq 10$ min per measurement day was studied. The total amount of VPA was low among overweight (mean $\leq 2.6 \mathrm{~min} /$ day), obese (mean $\leq 0.6 \mathrm{~min} / \mathrm{day}$ ) and all women in the age group 51-65 years (mean $\leq 2.5 \mathrm{~min} /$ day) during both types of days. The proportion of participants fulfilling the aerobic physical activity recommendation was highest for normal weight men (65\%; $95 \% \mathrm{Cl} 62 \%$ to $67 \%)$ and lowest for obese women (10\%; $95 \% \mathrm{Cl} 8 \%$ to $12 \%)$.

Conclusions: Objectively measured physical activity is higher among men and during days off, and decreases with increasing age and BMI. The amount of VPA is very low among obese, overweight and older women.

\section{INTRODUCTION}

Epidemiological evidence, studies on underlying mechanisms and intervention studies suggest that physical activity plays an
Strengths and limitations of this study

- By using this novel validated methodology, our study provides accurate data on intensity-specific physical activity in a large sample of working age individuals, with detailed associations between intensity-specific physical activity and gender, age, body mass index, and the type of day (workday vs day off), and their interactions.

- The study sample was not a random sample taken from the population, but a 'real-life' clinical sample of employees who participated in these preventive occupational healthcare activities.

- Our recordings usually covered some typical workdays and days off, but a longer recording may be more valid than the duration used in our study.

important role in the prevention of body fat accumulation and type 2 diabetes. ${ }^{1-5}$ Observational studies suggest that physical activity may also have other health benefits such as reduced risk for cardiovascular disease ${ }^{6-8}$ dementia $^{8}$ depression ${ }^{9}$ and mortality. ${ }^{10}$ To achieve these health benefits, according to recent recommendations, moderate-intensity aerobic physical activity should be performed for at least $150 \mathrm{~min}$ or vigorous physical activity (VPA) for at least 75 min per week. ${ }^{311} 12$ However, accurately recording the amount and intensity of physical activity with regard to activity-related energy requirements and cardiorespiratory loading is challenging. ${ }^{13}{ }^{14}$ Objective information is usually obtained by the heart rate (HR) monitors or motion sensors, such as accelerometers. ${ }^{15}$ Existing data suggest that, among obese individuals, the amount of VPA is low as compared with current recommendations. ${ }^{14}$ 16-18 However, estimating the cardiorespiratory loading of physical activity among obese and/or unfit individuals by using accelerometers or other motion sensors is difficult.

HR monitoring is a common method of assessing the intensity of physical activity in 
clinical settings. HR is almost linearly associated with oxygen consumption $\left(\mathrm{VO}_{2}\right)$ at moderate to submaximal intensities in steady-state exercise; therefore, it can be used to estimate the intensity of steady-state physical activity. However, the intensity of real-life physical activity usually changes repeatedly. Also the relationship between $\mathrm{HR}$ and $\mathrm{VO}_{2}$ is curvilinear for very low-intensity physical activities and near-maximal exercise. Therefore, the actual $\mathrm{VO}_{2}$ can be overestimated or underestimated by using the linear $\mathrm{HR}-\mathrm{VO}_{2}$ relationship to estimate the actual $\mathrm{VO}_{2} \cdot{ }^{19}$ Continuous measurement of HR variability and experimental calibration of data by age, gender, weight, height and self-reported physical activity class was recently shown to provide accurate estimates of the intensity of the physical activity. ${ }^{20}$ We used this novel methodology in the study to estimate the intensity of physical activity in a large sample of Finnish employees.

The aim of this study was to investigate the amount of physical activity among 9554 Finnish employees who had participated in the continuous beat-to-beat R-R interval (ECG) recordings during the course of their normal everyday life. More specifically, we investigated the intensity-specific amount of physical activity by gender and age with respect to body mass index (BMI) during workdays versus days off, including the hourly distribution of physical activity throughout the day. This information is an important basis for understanding the cardiorespiratory loading caused by physical activity, and the need and realistic possibilities for interventions that increase physical activity.

\section{METHODS}

\section{Study design and participants}

This study is a cross-sectional study investigating the intensity and amount of physical activity in a clinical sample of 9554 Finnish employees (4221 men and 5333 women; age range 18-65 years; BMI range $18.5-40 \mathrm{~kg}$ / $\mathrm{m}^{2}$ ) who participated in the preventive occupational healthcare activities provided by their employers during the years 2007-2013 (figure 1). The participants nonselectively represent a wide range of non-manual and manual labour employees and thus, a cross-section of typical Finnish employees. As a part of these healthcare programmes, participants performed continuous beat-to-beat $\mathrm{R}-\mathrm{R}$ interval recordings in the course of their normal everyday life as described below. The clinical purpose of these recordings was to assess the intensity and amount of physical activity (reported in this paper) and other R-R interval-derived information such as the amount of stress and recovery ${ }^{21}$ (not reported in this paper) during workdays and days off. To acquire these so-called Lifestyle Assessment results, the R-R interval data were analysed using Firstbeat Analysis Server software (Firstbeat Technologies Ltd, Jyväskylä, Finland). On the basis of the results, the participants received personal feedback and recommendations for maintaining or improving their health and well-being.

The majority of the participants in this study were apparently healthy. The exclusion criteria for participation in the R-R interval recordings represented by the analysis software manufacturer were: chronic heart rhythm disturbance, cardiac pacemaker or transplant, left bundle branch block, severe cardiac disease (eg, symptomatic coronary heart disease, heart failure), very high blood pressure $(\geq 180 / 100 \mathrm{~mm} \mathrm{Hg})$, type 1 or 2 diabetes with autonomic neuropathy, hyperthyreosis or other disturbances of the thyroid gland leading to a resting HR $>80 \mathrm{bpm}$, severe neurological disease (eg, advanced multiple sclerosis or Parkinson's disease), fever or other acute disease, and BMI $>40 \mathrm{~kg} / \mathrm{m}^{2}$. Cases
Figure 1 Flow of participants and measurement days included in the analysis (BMI, body mass index).

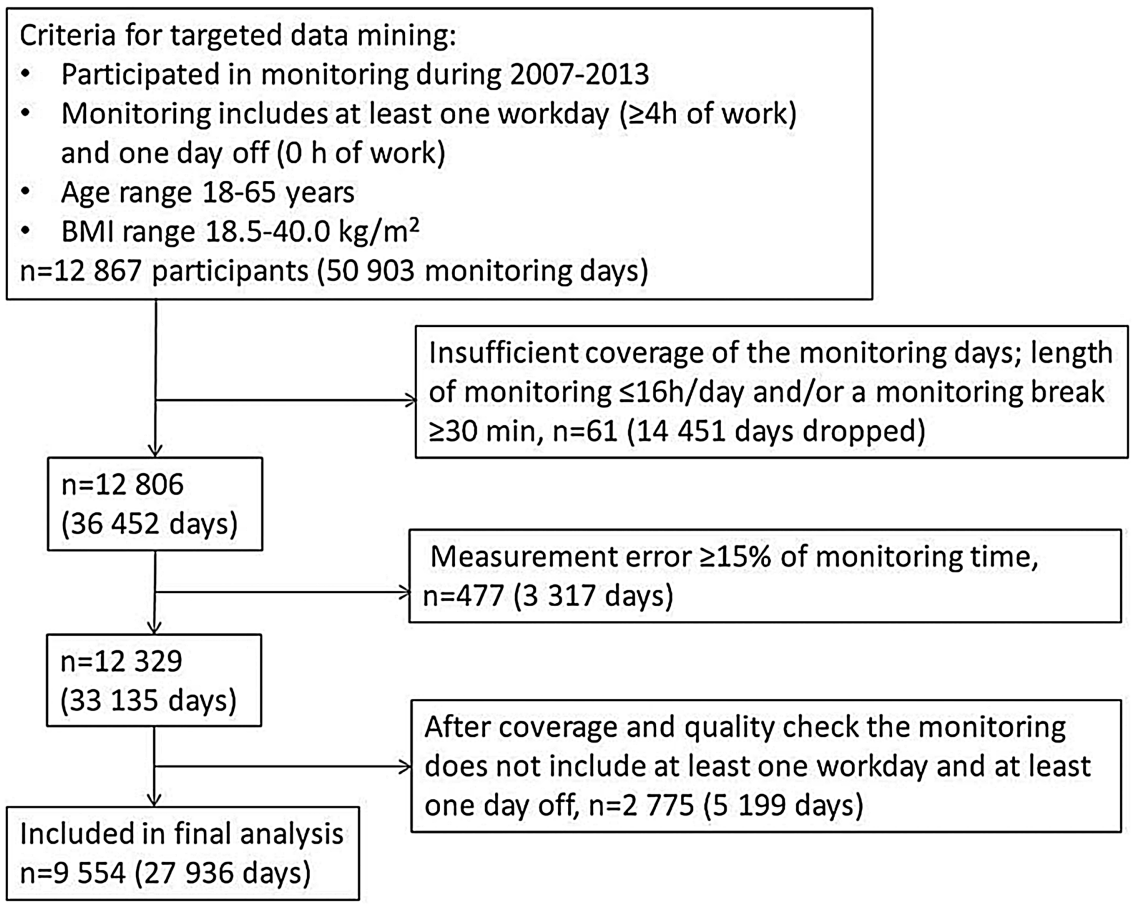


of milder/early disease stages and some medications may affect R-R intervals or physical activity levels. The inclusion/exclusion of these participants from the R-R interval recordings was evaluated on a case-by-case basis in the occupational healthcare programmes.

The data obtained from these R-R interval recordings were analysed and anonymously stored in a database administered by the software manufacturer (Firstbeat Technologies Ltd). Firstbeat Technologies Ltd and each service provider (eg, occupational healthcare unit) who conducted the recordings for the employees (participants) signed an agreement providing Firstbeat Technologies Ltd the right to store the data in an anonymised form and to use it for development and research purposes with a statement that employers must inform their employees about its use. According to the agreement, Firstbeat Technologies Ltd extracted an anonymous data file from the registry for the present research study.

\section{Physical activity assessment}

The ambulatory beat-to-beat R-R interval data used to calculate the intensity and amount of physical activity were recorded during the course of normal everyday life, usually over 3 days (typically including two workdays and one day off), using the Firstbeat Bodyguard device (Firstbeat Technologies Ltd). Data from the recordings were analysed using Firstbeat Analysis Server software (V.5.6.0.3, Firstbeat Technologies Ltd). To be included in the analyses (figure 1), a participant had to have a measurement period including at least one workday and one day off. We included a workday or a day off in the analysis if the measurement period lasted $>16 \mathrm{~h} /$ day. The information about workdays and days off was obtained from the diaries the participants were asked to fill in during the measurement period. A day was considered to be a workday if a participant worked $\geq 4 \mathrm{~h}$ cumulatively. The days without any working hours were regarded as days off and the days with work time $<4 \mathrm{~h}$ were excluded from the analyses. The analysed data consisted of successfully recorded (measurement error $<15 \%$ and $<30$ min recording break) workdays and days off (figure 1). The Firstbeat Bodyguard device cannot be used during swimming. Since we accepted only measurement days with $<30 \mathrm{~min}$ recording breaks, the days with longer watersports' sessions $(\geq 30 \mathrm{~min})$ are excluded from our analyses.

Background information which included age, gender, self-reported height and weight, and self-reported physical activity class $^{22}$ were modified from Ross and Jackson. ${ }^{23}$ This information was collected in conjunction with R-R interval recordings by using questionnaires. Background information was used to estimate maximal $\mathrm{HR}^{24}$ and maximal $\mathrm{VO}_{2},{ }^{25}$ which were then used in the estimation of $\mathrm{VO}_{2}$. If a period with $\mathrm{HR}$ higher than the estimated maximal was found from the recording, the maximal HR used for further calculations was corrected accordingly. For the statistical analyses, BMI was calculated from the self-reported weight and height as kilograms per metre squared.

The intensity and amount of physical activity was estimated based on the R-R interval recordings. ${ }^{26-29}$ The method was validated previously; the pooled relationship (correlation) between the measured and predicted $\mathrm{VO}_{2}$ across the different activities of daily living was 0.93 ; the estimated $\mathrm{VO}_{2}$ explained $87 \%$ of the variability in the measured $\mathrm{VO}_{2} \cdot{ }^{20}$ The high validity of this method was achieved by taking into account the R-R interval-derived information about $\mathrm{HR}$, respiration rate and on/off response (increasing or decreasing HR) using neural network modelling of the data and the short-time Fourier transform method. ${ }^{26-29}$

The participant's mean $\mathrm{VO}_{2}$ for each minute during each measurement day was calculated from the secondby-second $\mathrm{VO}_{2}$ estimations. The minute-by-minute $\mathrm{VO}_{2}$

Table 1 Distributions of participants into moderate-to-vigorous and vigorous physical activity categories according to mean minutes per day on workdays and days off

\begin{tabular}{|c|c|c|c|c|c|c|c|c|}
\hline & \multicolumn{4}{|l|}{ Workdays } & \multicolumn{4}{|l|}{ Days off } \\
\hline & $\begin{array}{l}\mathrm{O} \text { min } \\
\mathrm{n}(\%)\end{array}$ & $\begin{array}{l}>0-15 \mathrm{~min} \\
\mathrm{n}(\%)\end{array}$ & $\begin{array}{l}>15-30 \mathrm{~min} \\
\mathrm{n}(\%)\end{array}$ & $\begin{array}{l}>30 \text { min } \\
\mathrm{n}(\%)\end{array}$ & $\begin{array}{l}0 \mathrm{~min} \\
\mathrm{n}(\%)\end{array}$ & $\begin{array}{l}>0-15 \mathrm{~min} \\
\mathrm{n}(\%)\end{array}$ & $\begin{array}{l}>15-30 \mathrm{~min} \\
\mathrm{n}(\%)\end{array}$ & $\begin{array}{l}>30 \mathrm{~min} \\
\mathrm{n}(\%)\end{array}$ \\
\hline \multicolumn{9}{|l|}{ Men $(n=4221)$} \\
\hline $\mathrm{MVPA}_{1 \mathrm{~min}}$ & $91(2.2)$ & $835(19.8)$ & 706 (16.7) & $2589(61.3)$ & $160(3.8)$ & $851(20.2)$ & $563(13.3)$ & $2647(62.7)$ \\
\hline $\mathrm{MVPA}_{10 \mathrm{~min}}$ & 1345 (31.9) & 712 (16.9) & $802(19.0)$ & $1362(32.3)$ & $1535(36.4)$ & $452(10.7)$ & $500(11.8)$ & $1734(41.1)$ \\
\hline $\mathrm{VPA}_{1 \mathrm{~min}}$ & $1544(36.6)$ & $1571(37.2)$ & $658(15.6)$ & $448(10.6)$ & $1862(44.1)$ & $1221(28.9)$ & $391(9.3)$ & 747 (17.7) \\
\hline $\mathrm{VPA}_{10 \mathrm{~min}}$ & $3014(71.4)$ & $524(12.4)$ & $441(10.4)$ & $242(5.7)$ & $3189(75.6)$ & $236(5.6)$ & $292(6.9)$ & $504(11.9)$ \\
\hline \multicolumn{9}{|c|}{ Women $(n=5333)$} \\
\hline $\mathrm{MVPA}_{1 \mathrm{~min}}$ & $480(9.0)$ & $1632(30.6)$ & $1015(19.0)$ & $2206(41.4)$ & $838(15.7)$ & $1612(30.2)$ & $760(14.3)$ & $2123(39.8)$ \\
\hline $\mathrm{MVPA}_{10 \mathrm{~min}}$ & $2523(47.3)$ & $913(17.1)$ & 864 (16.2) & $1033(19.4)$ & 2999 (56.2) & $469(8.8)$ & $550(10.3)$ & $1315(24.7)$ \\
\hline $\mathrm{VPA}_{1 \mathrm{~min}}$ & $3200(60.0)$ & $1454(27.3)$ & $440(8.3)$ & $239(4.5)$ & 3651 (68.5) & 979 (18.4) & $299(5.6)$ & 404 (7.6) \\
\hline $\mathrm{VPA}_{10 \mathrm{~min}}$ & $4520(84.8)$ & $408(7.7)$ & $294(5.5)$ & $111(2.1)$ & 4690 (87.9) & $196(3.7)$ & 169 (3.2) & $278(5.2)$ \\
\hline
\end{tabular}

$\mathrm{MVPA}_{1 \mathrm{~min}}$, moderate-to-vigorous physical activity ( $\geq 3$ metabolic equivalents (METs)) calculated from single 1 min bouts throughout the measurement period.

$M_{V P A} 10$ min, moderate-to-vigorous physical activity ( $\geq 3$ METs) calculated from bouts of physical activity lasting continuously for $\geq 10$ min.

$V_{P A} A_{1 \text { min }}$, vigorous physical activity ( $\geq 6 \mathrm{METs}$ ) calculated from single 1 min bouts throughout the measurement period.

VPA $_{10 \mathrm{~min}}$, vigorous physical activity ( $\geq 6 \mathrm{METs}$ ) calculated from bouts of physical activity lasting continuously for $\geq 10 \mathrm{~min}$. 

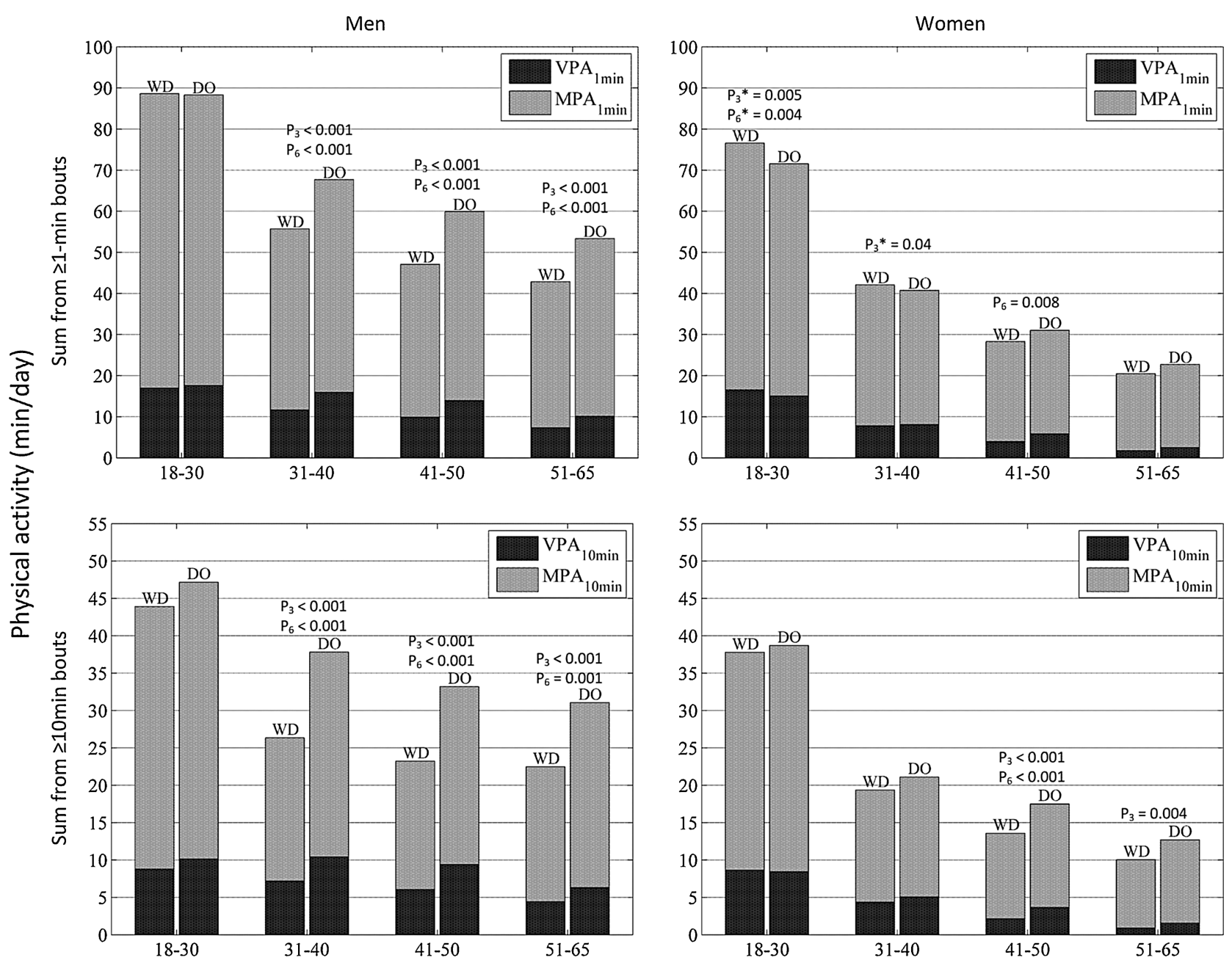

Figure 2 The mean amount of moderate-to-vigorous physical activity ( $\geq 3$ metabolic equivalents (METs); whole column) and its distribution into moderate (MPA; 3 to $<6$ METs) and vigorous (VPA; $\geq 6$ METs) physical activity during workdays (WD) and days off (DO) by age among men and women. The 1 min notation indicates values for single 1 min bouts throughout the measurement period, whereas the 10 min notation indicates values for bouts of physical activity lasting continuously for $\geq 10$ min. $P_{3}$ and $P_{6}$ denote the differences between WD and DO in moderate-to-vigorous physical activity and VPA, respectively. ${ }^{*}$ Physical activity was greater during WD than DO. Note the different scales between the upper and lower figures.

estimates were then converted to multiples of the resting metabolic rate (metabolic equivalents, METs) by dividing the $\mathrm{VO}_{2}$ values by 3.5. On the basis of the MET values, the amount of physical activity (min/day) at a certain intensity level was calculated in two ways. First, we searched the recordings for single $1 \mathrm{~min}$ segments in which the intensity reached the following MET thresholds: moderate physical activity (MPA) 3 to $<6$ METs, VPA $\geq 6$ METs, and moderate-to-vigorous physical activity (MVPA) $\geq 3 \mathrm{METs}^{12}$; these are referred to as $\mathrm{MPA}_{1 \min }, \mathrm{VPA}_{1 \text { min }}$ and $\mathrm{MVPA}_{1 \text { min }}$ later in the text. The total number of 1 min segments above the given thresholds during each measurement day was then calculated. These calculations were performed separately for workdays and days off. If a participant's measurement period included two or more workdays (or days off), an average was calculated. Second, because the recommendation for health-enhancing physical activity suggests that the duration of a bout of aerobic activity should be 10 continuous minutes or longer, ${ }^{3} 1112$ we utilised this in our calculations for different intensity categories; these are referred to as $\mathrm{MPA}_{10 \mathrm{~min}}, \mathrm{VPA}_{10 \text { min }}$ and $\mathrm{MVPA}_{10 \text { min }}$ later in the text. In this case, we calculated the total number of 1 min segments above the given intensity thresholds during each measurement day using only the bouts of physical activity that lasted continuously for $\geq 10 \mathrm{~min}$. The consecutive $1 \mathrm{~min}$ segments had to be above the given intensity thresholds for at least $10 \mathrm{~min}$, except for a single $1 \mathrm{~min}$ segment which was allowed to be less than the given threshold. Otherwise, the calculations were performed using the same principles as described above for single $1 \mathrm{~min}$ segment.

\section{Analysis}

Data processing and statistical analysis were performed using MATLAB version R2013b (The MathWorks Inc, Natick, Massachusetts, USA) and R V.3.0.2 (The R 
Table 2 Amount of moderate-to-vigorous and vigorous physical activity during workdays and days off based on age group

\begin{tabular}{|c|c|c|c|c|c|c|c|c|}
\hline & \multirow[b]{2}{*}{$\begin{array}{l}\text { n (men/ } \\
\text { women) }\end{array}$} & & \multicolumn{3}{|l|}{ Men } & \multicolumn{3}{|l|}{ Women } \\
\hline & & & $\begin{array}{l}\text { Workdays } \\
\text { (min/day) }\end{array}$ & $\begin{array}{l}\text { Days off } \\
\text { (min/day) }\end{array}$ & p Value* & $\begin{array}{l}\text { Workdays } \\
\text { (min/day) }\end{array}$ & $\begin{array}{l}\text { Days off } \\
\text { (min/day) }\end{array}$ & p Value \\
\hline \multicolumn{9}{|l|}{$\mathrm{MVPA}_{1 \mathrm{~min}}$} \\
\hline 18-30 years & $366 / 457$ & $\begin{array}{l}\text { Mean (SD) } \\
\text { Median }\end{array}$ & $\begin{array}{l}88.6(72.8) \dagger \\
67.5 \dagger\end{array}$ & $\begin{array}{l}88.3(75.7) \dagger \\
69.0 \dagger\end{array}$ & 0.81 & $\begin{array}{l}76.6(53.5) \dagger \\
69.0 \dagger\end{array}$ & $\begin{array}{l}71.5(61.9) \dagger \\
60.0 \dagger\end{array}$ & 0.005 \\
\hline $31-40$ years & $1109 / 1251$ & $\begin{array}{l}\text { Mean (SD) } \\
\text { Median }\end{array}$ & $\begin{array}{l}55.7(44.2) \dagger \\
47.0 \dagger\end{array}$ & $\begin{array}{l}67.7(63.2) \dagger \\
52.3 \dagger\end{array}$ & $<0.001$ & $\begin{array}{l}42.1(38.5) \dagger \\
34.0 \dagger\end{array}$ & $\begin{array}{l}40.8(40.6) \dagger \\
28.0 \dagger\end{array}$ & 0.041 \\
\hline $41-50$ years & $1411 / 1905$ & $\begin{array}{l}\text { Mean (SD) } \\
\text { Median }\end{array}$ & $\begin{array}{l}47.1(42.5) \dagger \\
36.5 \dagger\end{array}$ & $\begin{array}{l}59.9(56.5) \dagger \\
47.0 \dagger\end{array}$ & $<0.001$ & $\begin{array}{l}28.3(29.1) \dagger \\
21.0 \dagger\end{array}$ & $\begin{array}{l}31.1(37.1) \dagger \\
17.0 \dagger\end{array}$ & 0.34 \\
\hline $51-65$ years & $1335 / 1720$ & $\begin{array}{l}\text { Mean (SD) } \\
\text { median }\end{array}$ & $\begin{array}{l}42.9(46.2) \dagger \\
31.0 \dagger\end{array}$ & $\begin{array}{l}53.3(56.0) \dagger \\
37.5 \dagger\end{array}$ & $<0.001$ & $\begin{array}{l}20.5(24.4) \dagger \\
11.0 \dagger\end{array}$ & $\begin{array}{l}22.7(33.3) \dagger \\
8.0 \dagger\end{array}$ & 0.74 \\
\hline \multicolumn{9}{|l|}{$\mathrm{VPA}_{1 \text { min }}$} \\
\hline 18-30 years & $366 / 457$ & $\begin{array}{l}\text { Mean (SD) } \\
\text { median }\end{array}$ & $\begin{array}{l}17.0(21.4) \dagger \\
10.0 \dagger\end{array}$ & $\begin{array}{l}17.6(25.3) \dagger \\
5.0 \dagger\end{array}$ & 0.73 & $\begin{array}{l}16.5(19.9) \dagger \\
9.0 \dagger\end{array}$ & $\begin{array}{l}15.1(23.1) \dagger \\
4.0 \dagger\end{array}$ & 0.004 \\
\hline $31-40$ years & $1109 / 1251$ & $\begin{array}{l}\text { Mean (SD) } \\
\text { Median }\end{array}$ & $\begin{array}{l}11.6(16.6) \dagger \\
4.0 \dagger\end{array}$ & $\begin{array}{l}15.9(24.4) \dagger \\
3.0 \dagger\end{array}$ & $<0.001$ & $\begin{array}{l}7.8(12.7) \dagger \\
1.0 \dagger\end{array}$ & $\begin{array}{l}8.1(15.9) \dagger \\
0.0 \dagger\end{array}$ & 0.16 \\
\hline $41-50$ years & $1411 / 1905$ & $\begin{array}{l}\text { Mean (SD) } \\
\text { Median }\end{array}$ & $\begin{array}{l}9.9(14.7) \dagger \\
2.0 \dagger\end{array}$ & $\begin{array}{l}13.9(24.9) \dagger \\
1.0 \dagger\end{array}$ & $<0.001$ & $\begin{array}{l}4.0(9.1) \dagger \\
0.0 \dagger\end{array}$ & $\begin{array}{l}5.8(14.9) \dagger \\
0.0 \dagger\end{array}$ & 0.008 \\
\hline $51-65$ years & $1335 / 1720$ & $\begin{array}{l}\text { Mean (SD) } \\
\text { Median }\end{array}$ & $\begin{array}{l}7.4(13.9) \dagger \\
0.5 \dagger\end{array}$ & $\begin{array}{l}10.2(21.2) \dagger \\
0.0 \dagger\end{array}$ & $<0.001$ & $\begin{array}{l}1.8(6.3) \dagger \\
0.0 \dagger\end{array}$ & $\begin{array}{l}2.5(11.2) \dagger \\
0.0 \dagger\end{array}$ & 0.54 \\
\hline
\end{tabular}

${ }^{*}$ For the difference between workdays and days off by Wilcoxon two-sample paired signed rank test.

$t p<0.001$ for the difference between age groups by Kruskal-Wallis test.

$\mathrm{MVPA}_{1 \mathrm{~min}}$, moderate-to-vigorous physical activity ( $\geq 3$ metabolic equivalents (METs)) calculated from single 1 min bouts throughout the measurement period.

VPA $_{1 \text { min }}$, vigorous physical activity ( $\geq 6$ METs) calculated from single 1 min bouts throughout the measurement period.

Foundation for Statistical Computing, Vienna, Austria). All $\mathrm{p}$ values were two-sided and $\mathrm{p}<0.05$ was considered statistically significant.

We calculated means, SDs and medians for continuous variables, and frequencies and proportions for categorical variables. We categorised the amount of MVPA and VPA into four categories $(0,>0-15,>15-30$ and $>30 \mathrm{~min}$ ) and calculated the distribution of participants in these categories by gender and type of day (ie, workdays vs days off). We also calculated the amount of MVPA and VPA by gender and type of day for different age categories (18-30, 31-40, 41-50 and 51-65 years) and BMI categories (normal weight 18.5 to $<25 \mathrm{~kg} / \mathrm{m}^{2}$; overweight 25 to $<30 \mathrm{~kg} / \mathrm{m}^{2}$; and obese $30-40 \mathrm{~kg} / \mathrm{m}^{2}$ ). The amount of MVPA and VPA during the workdays and days off were compared by gender for each age and BMI category by using the Wilcoxon two-sample paired signed rank test. The test assessed whether the differences in the amount of MVPA and VPA between each participant's workdays and days off came from a distribution with a median of zero. Differences in the amount of MVPA and VPA between age categories and BMI categories were analysed using the Kruskal-Wallis test. To describe the temporal distribution of physical activity, we calculated the amount of MVPA and VPA done in each hour (eg, from 9:00 to 10:00, from 10:00 to 11:00, etc.) during the day by gender, BMI category and type of day. For illustrative purposes, the means are shown in all figures instead of medians.
The probability of having at least one $10 \mathrm{~min}$ bout of MVPA or VPA per measurement day (binary outcome; yes vs no) was modelled using a generalised linear mixed-effects regression (procedure glmer with Laplace approximation in R). Each participant was incorporated as a random effect; fixed effects included age and BMI as continuous variables and gender and type of day as binary variables. In the modelling, we also included all the possible two-way interactions among these four variables. We also used linear mixed-effects regression (procedure fitlme with maximum likelihood estimation in MATLAB) to predict the amount of $\mathrm{MVPA}_{1 \text { min }}$ and $\mathrm{VPA}_{1 \mathrm{~min}}$. In this case, each participant was incorporated as a random effect while fixed effects included age, BMI, gender and type of day. The baselines for age (minimum 18 years) and BMI (minimum $18.5 \mathrm{~kg} / \mathrm{m}^{2}$ ) were subtracted from age and BMI data, respectively, before the regression calculations.

We also investigated how participants fulfil the aerobic physical activity recommendations of moderate-intensity physical activity for at least 150 min or VPA for at least 75 min per week as measured from the $\geq 10 \mathrm{~min}$ bouts of activity. ${ }^{3}$ First, we calculated the activity minutes score for each day (MPA minutes+VPA minutes $\times 2$ ) and then extrapolated the amount of physical activity using the following formula: Weekly physical activity $=(5 \times$ mean workday activity score $)+(2 \times$ mean day off activity score $)$. This calculation was performed for only those bouts of 
Men

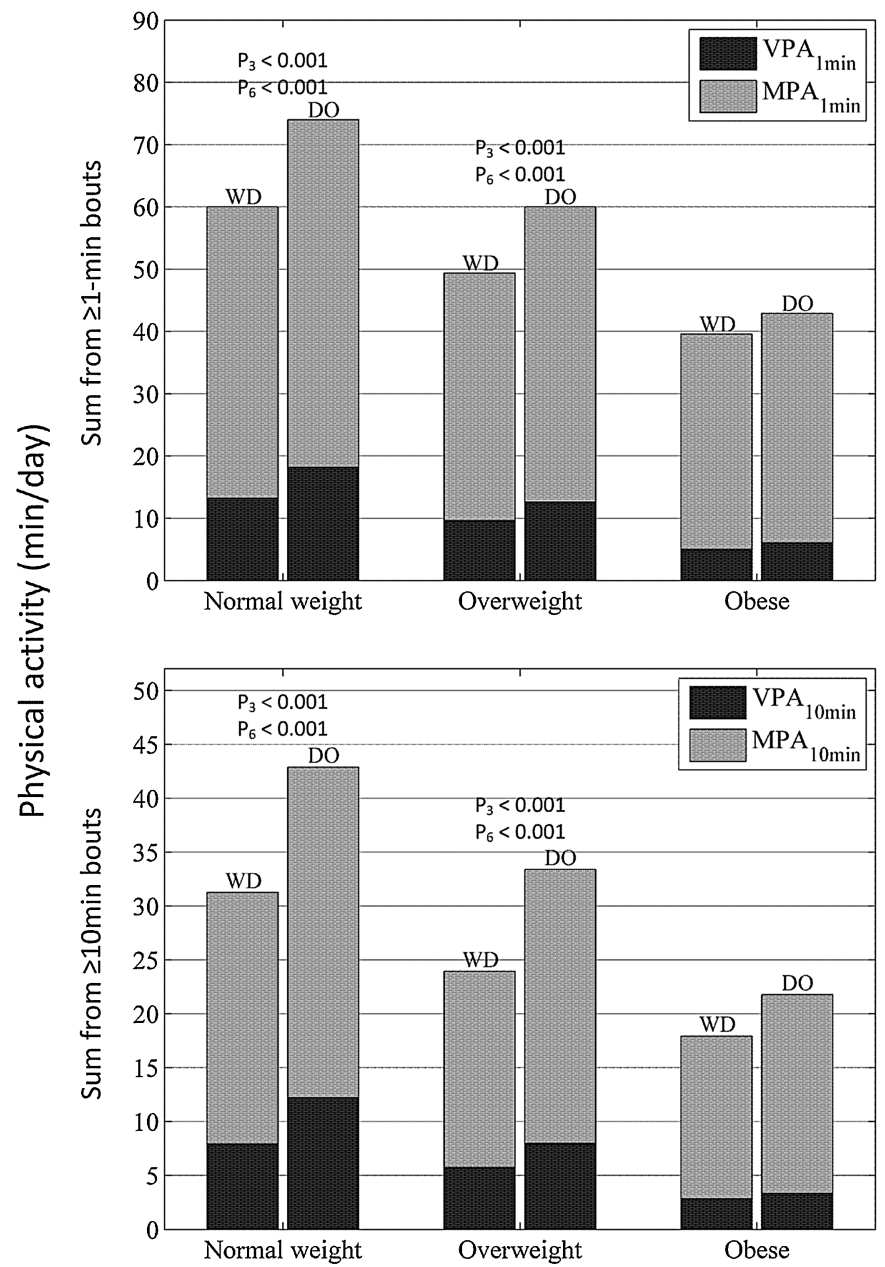

Women
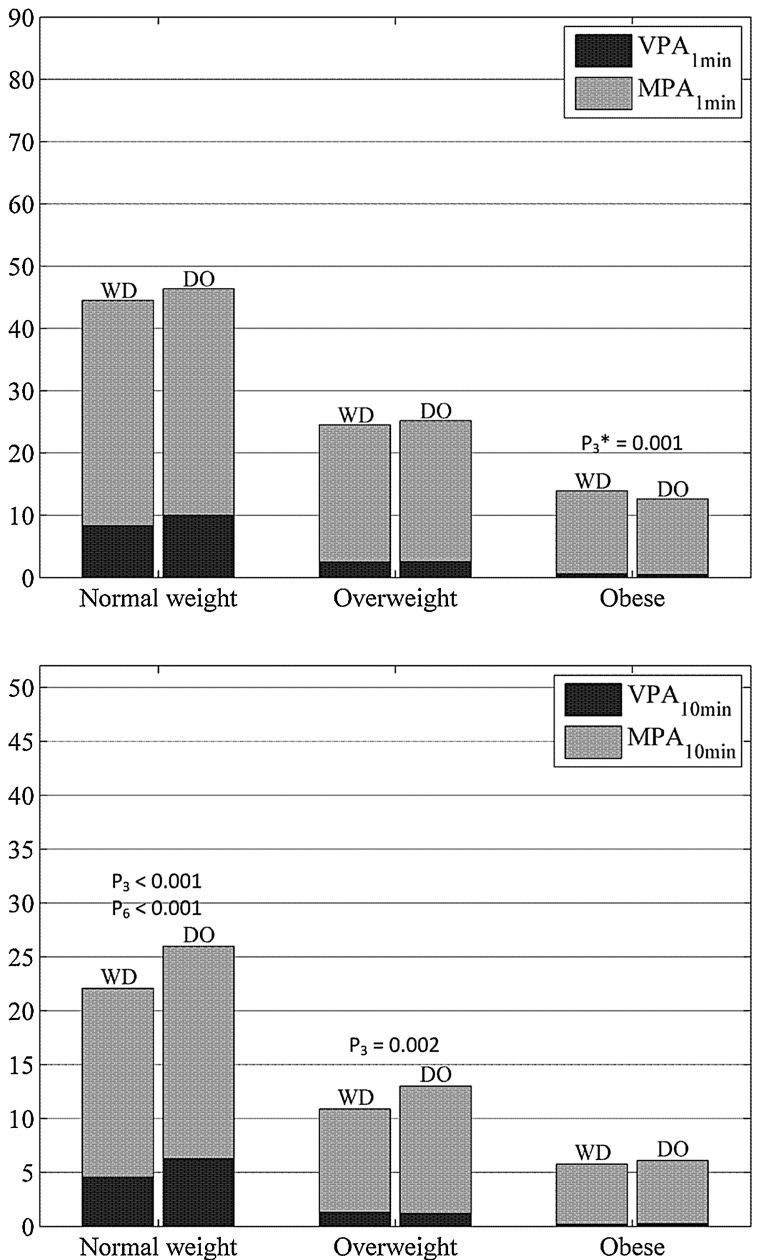

Figure 3 The mean amount of moderate-to-vigorous physical activity ( $\geq 3$ metabolic equivalents (METs); whole column) and its distribution into moderate (MPA; 3 to $<6$ METs) and vigorous (VPA; $\geq 6$ METs) physical activity during workdays (WD) and days off (DO) by weight status among men and women. Normal weight $=18.5$ to $<25 \mathrm{~kg} / \mathrm{m}^{2}$; overweight=25 to $<30 \mathrm{~kg} / \mathrm{m}^{2} ;$ obese $=30-$ $40 \mathrm{~kg} / \mathrm{m}^{2}$. The $1 \mathrm{~min}$ notation indicates values for single $1 \mathrm{~min}$ bouts throughout the measurement period, whereas the $10 \mathrm{~min}$ notation indicates values for bouts of physical activity lasting continuously for $\geq 10$ min. $P_{3}$ and $P_{6}$ denote the differences between WD and DO in moderate-to-vigorous physical activity and VPA, respectively. ${ }^{*}$ Physical activity was greater during WD than DO. Note the different scales between the upper and lower figures.

physical activity lasting continuously for $\geq 10 \mathrm{~min}$ as recommended, ${ }^{3}$ and then for all $\geq 1$ min bouts.

\section{RESULTS}

Most of the R-R-interval recordings were from 3 days (7685 participants); there were 1394, 319, 119 and 37 participants who had two, four, five and six measurement days, respectively. Altogether, the number of analysed days was 17020 workdays and 10916 days off. The mean (SD) age of the participants was 44.8 (9.7) years (men 44.7 (9.7); women $44.9(9.7))$ and the mean (SD) BMI was 26.1 (4.1) $\mathrm{kg} / \mathrm{m}^{2}$ (men 26.7 (3.5); women 25.7 (4.4)).

Table 1 shows the distribution of participants in the MVPA and VPA categories by workdays and days off among the 4221 men and 5333 women who participated in this study. For more than $60 \%$ of the men and approximately $40 \%$ of the women, the amount of
$\mathrm{MVPA}_{1 \text { min }}$ was more than $30 \mathrm{~min} /$ day (regardless of the type of day), whereas $11 \%$ (workdays) and $18 \%$ (days off) of men and $4 \%$ (workdays) and $8 \%$ (days off) of women had $\mathrm{VPA}_{1 \mathrm{~min}}$ for more than $30 \mathrm{~min} /$ day. All these percentages were clearly lower for $\mathrm{MVPA}_{10 \mathrm{~min}}$ and $\mathrm{VPA}_{10}$ min

Figure 2 and table 2 show the amount of MVPA and VPA by age, gender and the type of day. The amount of MVPA and VPA decreased with advancing age, especially among women. Among men aged 31 years and above, the amounts of $\mathrm{MVPA}_{1 \mathrm{~min}}, \mathrm{MVPA}_{10 \text { min }}, \mathrm{VPA}_{1 \text { min }}$ and $\mathrm{VPA}_{10}$ min were greater during days off than during workdays. Among younger women (18-40 years), the amount of $\mathrm{MVPA}_{1 \text { min }}$ was lower during days off as compared with working days, whereas the amount of $\mathrm{MVPA}_{10 \text { min }}$ was higher during days off among older women (4165 years). Other clear trends were not observed among the women. 
Table 3 Amount of moderate-to-vigorous and vigorous physical activity during workdays and days off based on weight status

\begin{tabular}{|c|c|c|c|c|c|c|c|c|}
\hline & \multirow[b]{2}{*}{$\begin{array}{l}\text { n (men/ } \\
\text { women) }\end{array}$} & & \multicolumn{3}{|l|}{ Men } & \multicolumn{3}{|l|}{ Women } \\
\hline & & & $\begin{array}{l}\text { Workdays } \\
\text { (min/day) }\end{array}$ & $\begin{array}{l}\text { Days off } \\
\text { (min/day) }\end{array}$ & p Value* & $\begin{array}{l}\text { Workdays } \\
\text { (min/day) }\end{array}$ & $\begin{array}{l}\text { Days off } \\
\text { (min/day) }\end{array}$ & p Value* \\
\hline \multicolumn{9}{|l|}{$\mathrm{MVPA}_{1 \text { min }}$} \\
\hline Normal weight & $1495 / 2792$ & $\begin{array}{l}\text { Mean (SD) } \\
\text { Median }\end{array}$ & $\begin{array}{l}60.1(53.5) \dagger \\
48.0 \dagger\end{array}$ & $\begin{array}{l}74.0(67.4) \dagger \\
58.5 \dagger\end{array}$ & $<0.001$ & $\begin{array}{l}44.5(39.6) \dagger \\
35.5 \dagger\end{array}$ & $\begin{array}{l}46.4(46.7) \dagger \\
35.0 \dagger\end{array}$ & 0.99 \\
\hline Overweight & $2067 / 1627$ & $\begin{array}{l}\text { Mean (SD) } \\
\text { Median }\end{array}$ & $\begin{array}{l}49.4(46.2) \dagger \\
38.0 \dagger\end{array}$ & $\begin{array}{l}60.0(56.4) \dagger \\
46.0 \dagger\end{array}$ & $<0.001$ & $\begin{array}{l}24.5(30.1) \dagger \\
16.0 \dagger\end{array}$ & $\begin{array}{l}25.2(33.0) \dagger \\
12.0 \dagger\end{array}$ & 0.60 \\
\hline Obese & $659 / 914$ & $\begin{array}{l}\text { Mean (SD) } \\
\text { median }\end{array}$ & $\begin{array}{l}39.6(43.5) \dagger \\
29.0 \dagger\end{array}$ & $\begin{array}{l}42.9(52.0) \dagger \\
26.0 \dagger\end{array}$ & 0.18 & $\begin{array}{l}13.9(21.3) \dagger \\
4.8 \dagger\end{array}$ & $\begin{array}{l}12.6(21.8) \dagger \\
2.0 \dagger\end{array}$ & 0.001 \\
\hline \multicolumn{9}{|l|}{$\mathrm{VPA}_{1 \text { min }}$} \\
\hline Normal weight & $1495 / 2792$ & $\begin{array}{l}\text { Mean (SD) } \\
\text { Media } n\end{array}$ & $\begin{array}{l}13.2(17.3) \dagger \\
5.5 \dagger\end{array}$ & $\begin{array}{l}18.2(27.4) \dagger \\
4.0 \dagger\end{array}$ & $<0.001$ & $\begin{array}{l}8.4(13.8) \dagger \\
1.0 \dagger\end{array}$ & $\begin{array}{l}10.0(19.2) \dagger \\
0.0 \dagger\end{array}$ & 0.65 \\
\hline Overweight & $2067 / 1627$ & $\begin{array}{l}\text { Mean (SD) } \\
\text { median }\end{array}$ & $\begin{array}{l}9.6(15.5) \dagger \\
1.5 \dagger\end{array}$ & $\begin{array}{l}12.6(22.3) \dagger \\
1.0 \dagger\end{array}$ & $<0.001$ & $\begin{array}{l}2.5(7.9) \dagger \\
0.0 \dagger\end{array}$ & $\begin{array}{l}2.6(9.1) \dagger \\
0.0 \dagger\end{array}$ & 0.44 \\
\hline Obese & $659 / 914$ & $\begin{array}{l}\text { Mean (SD) } \\
\text { Median }\end{array}$ & $\begin{array}{l}5.0(11.3) \dagger \\
0.0 \dagger\end{array}$ & $\begin{array}{l}6.1(16.3) \dagger \\
0.0 \dagger\end{array}$ & 0.97 & $\begin{array}{l}0.6(3.1) \dagger \\
0.0 \dagger\end{array}$ & $\begin{array}{l}0.5(3.5) \dagger \\
0.0 \dagger\end{array}$ & 0.07 \\
\hline
\end{tabular}

Normal weight $=18.5$ to $<25 \mathrm{~kg} / \mathrm{m}^{2}$; overweight $=25$ to $<30 \mathrm{~kg} / \mathrm{m}^{2}$; obese $=30-40 \mathrm{~kg} / \mathrm{m}^{2}$.

${ }^{*}$ For the difference between workdays and days off by Wilcoxon two-sample paired signed rank test.

$t p<0.001$ for the difference between body mass index groups by Kruskal-Wallis test.

$\mathrm{MVPA}_{1 \text { min }}$, moderate-to-vigorous physical activity ( $\geq 3$ metabolic equivalents (METs)) calculated from single 1 min bouts throughout the measurement period.

VPA $_{1 \text { min }}$, vigorous physical activity ( $\geq 6 \mathrm{METs}$ ) calculated from single 1 min bouts throughout the measurement period.

Figure 3 and table 3 show the amount of MVPA and VPA by weight status, gender and the type of day. Obese participants had less MVPA and VPA than normal weight and overweight participants, especially women. The mean amount of $\mathrm{VPA}_{1}$ min was approximately $0.5 \mathrm{~min} /$ day among obese women, for workdays and days off. Among obese men, the mean amount of $\mathrm{VPA}_{1 \text { min }}$ was 5 min during workdays and 6.1 min during days off. The mean amount of $\mathrm{VPA}_{1 \text { min }}$ was also low among overweight women $(\sim 2.5 \mathrm{~min} /$ day for workdays and days off). Among normal weight and overweight men, the amount of $\mathrm{MVPA}_{1 \mathrm{~min}}, \mathrm{MVPA}_{10 \mathrm{~min}}, \mathrm{VPA}_{1 \mathrm{~min}}$ and $\mathrm{VPA}_{10 \text { min }}$ were all greater during days off than on workdays, but these differences were not observed among obese men. The corresponding results for women were more complex. Normal weight and overweight women had more $\mathrm{MVPA}_{10 \text { min }}$ during days off than during workdays. However, the amount of $\mathrm{MVPA}_{1 \text { min }}$ was similar for both types of days. However, obese women had a lower amount of $\mathrm{MVPA}_{1 \text { min }}$ during days off than on workdays, but the amount of $\mathrm{MVPA}_{10}$ min was similar for both types of days. Differences between workdays and days off with regard to VPA were observed for normal weight women; $\mathrm{VPA}_{10}$ min was higher during days off than on workdays.

Hourly distributions of MVPA and VPA by gender, weight status and type of day are shown in figure 4 . The largest amounts of MVPA during workdays occurred at 7:00-8:00 and 17:00-19:00. During days off, the largest amounts of MVPA were distributed evenly between 10:00 and 18:00. The respective VPA profiles resemble those of MVPA. During workdays, a small peak occurred at 7:00-8:00, but the greatest amount of VPA was clearly seen during 17:00-20:00. The greatest amount of VPA during days off occurred between 10:00 and 20:00. For both genders, the amount of MVPA and VPA during workdays and days off decreased with increasing BMI.

When age, gender, BMI and the type of day were included in the linear mixed-effects regression models as predictors of the amount of $\mathrm{MVPA}_{1 \mathrm{~min}}$ or $\mathrm{VPA}_{1 \mathrm{~min}}$ (table 4), the predictors associated with both outcome measures in similar manner. The amount of $\mathrm{MVPA}_{1 \text { min }}$ and $\mathrm{VPA}_{1 \text { min }}$ decreased with increasing age and increasing BMI. The amounts of $\mathrm{MVPA}_{1 \text { min }}$ and $\mathrm{VPA}_{1 \text { min }}$ were higher among men as compared with women and higher for days off than for the workdays $(p<0.001$ for all). Similar results were observed when we studied the probability of having a bout of MVPA or VPA (per measurement day) that lasted continuously for $\geq 10 \mathrm{~min}$ (table 5). The probability was higher among men and during days off, and it decreased with increasing age and increasing BMI ( $\mathrm{p}<0.001$ for all).

We also performed multivariate analysis for the probability of having a bout of MVPA or VPA lasting continuously for $\geq 10 \mathrm{~min}$ including two-way interactions between age, gender, BMI and the type of day (table 5). Many statistically significant interactions were observed between these variables. Both higher BMI and higher age decreased the likelihood of participation in MVPA or VPA, but BMI affected the older participants more than the younger participants. In addition, the women were more affected by higher age or higher BMI than men. With increasing age, the probability of MVPA or VPA increased for days off as compared with workdays. With increasing BMI, the probability of MVPA and VPA increased for workdays as compared with days off. 


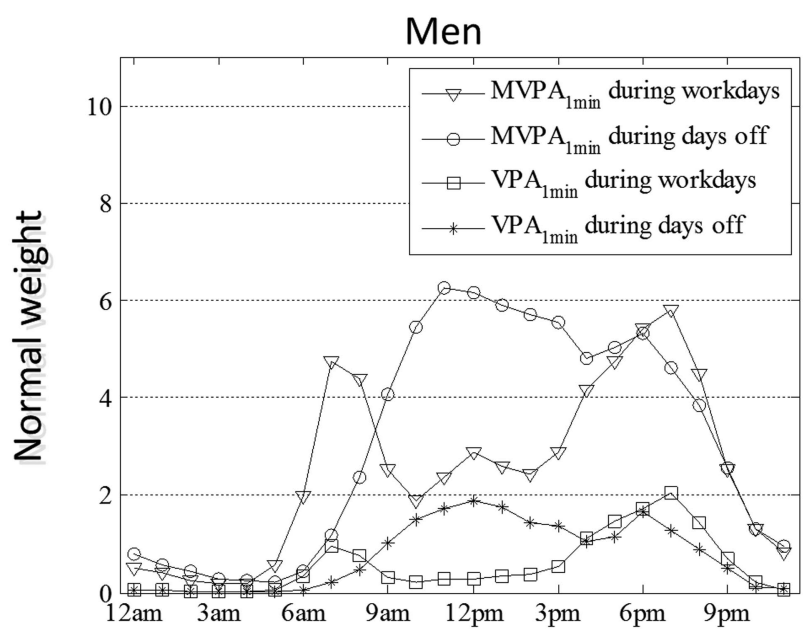

Women
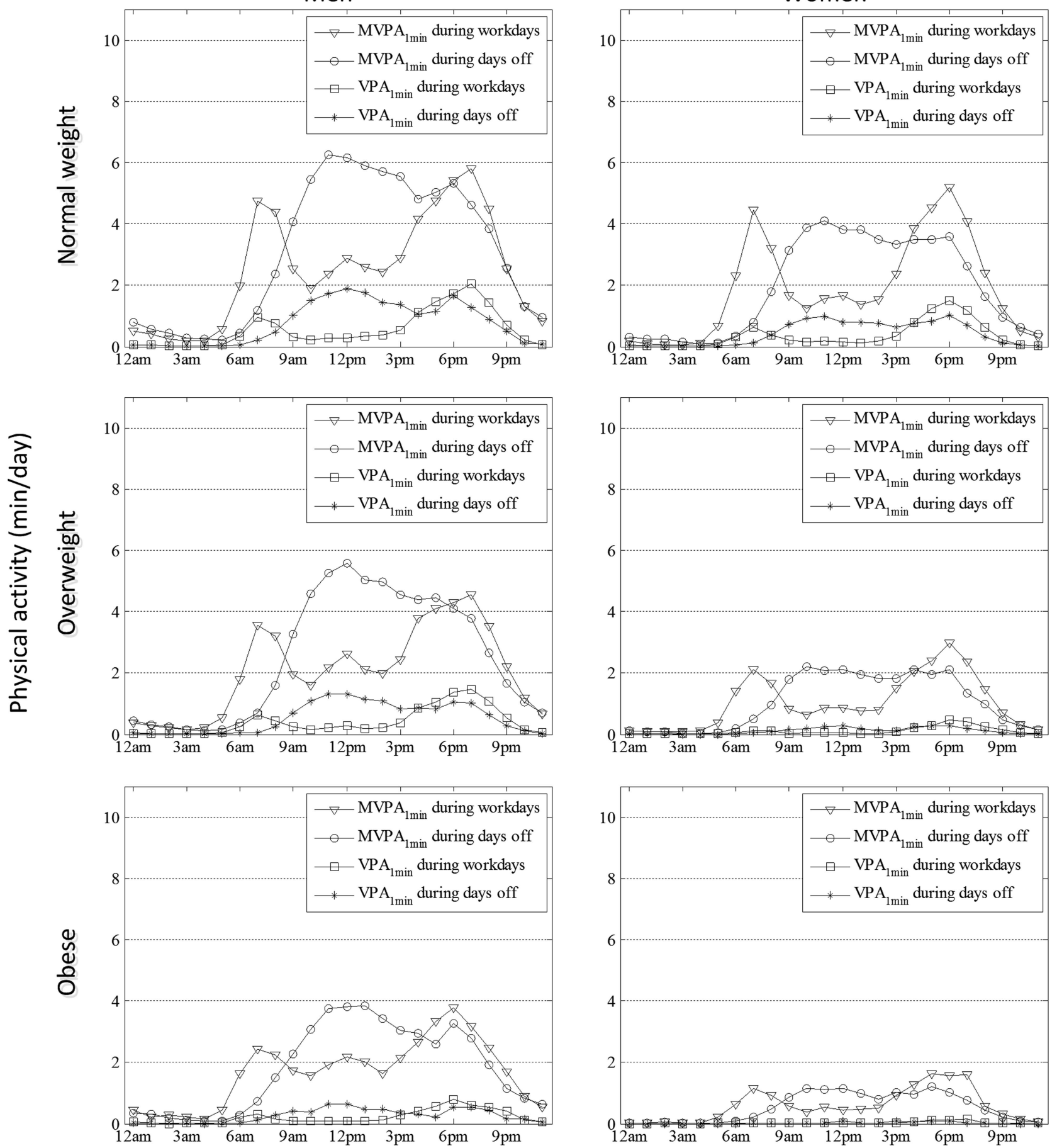

Figure 4 Hourly distributions of moderate-to-vigorous (MVPA; $\geq 3$ metabolic equivalents (METs)) and vigorous (VPA; $\geq 6$ METs) physical activity by gender and weight status during workdays and days off. The mean number of minutes at a certain hour (eg, 9:00) denotes the number of minutes during the hour beginning from that time point (eg, 9:00-10:00. Normal weight=18.5 to $<25 \mathrm{~kg} / \mathrm{m}^{2}$; overweight $=25$ to $<30 \mathrm{~kg} / \mathrm{m}^{2}$; obese $=30-40 \mathrm{~kg} / \mathrm{m}^{2}$. The $1 \mathrm{~min}$ notation indicates values for single $1 \mathrm{~min}$ bouts throughout the measurement period.

The percentages of participants (by gender and weight status) who fulfilled the aerobic physical activity recommendations are provided in figure 5 and table 6 . The proportion of participants fulfilling the recommendations decreased with increasing BMI for men and women. The same was true when the weekly physical activity was calculated including all $\geq 1$ min bouts. Men fulfilled the recommendations better than women. The proportion fulfilling the recommendations was highest among normal weight men $(64.9 \%, 95 \%$ CI $62.4 \%$ to 
Table 4 Predictors of the amount of moderate-to-vigorous and vigorous physical activity

\begin{tabular}{|c|c|c|c|c|}
\hline & \multicolumn{2}{|l|}{$\mathrm{MVPA}_{1 \mathrm{~min}}$} & \multicolumn{2}{|l|}{$V_{P A} \min$} \\
\hline & $\begin{array}{l}\text { Unstandardised regression } \\
\text { coefficient }(95 \% \mathrm{Cl})\end{array}$ & p Value & $\begin{array}{l}\text { Unstandardised regression } \\
\text { coefficient }(95 \% \mathrm{Cl})\end{array}$ & p Value \\
\hline Age $(18$ years $=0)$ & $-1.130(-1.203$ to -1.056$)$ & $<0.001$ & $-0.286(-0.310$ to -0.261$)$ & $<0.001$ \\
\hline Gender ( $1=$ men; $0=$ women $)$ & 24.352 (22.930 to 25.773$)$ & $<0.001$ & 6.584 (6.114 to 7.054$)$ & $<0.001$ \\
\hline Body mass index $\left(18.5 \mathrm{~kg} / \mathrm{m}^{2}=0\right)$ & $-2.464(-2.639$ to -2.288$)$ & $<0.001$ & $-0.762(-0.820$ to -0.704$)$ & $<0.001$ \\
\hline Type of day ( $1=$ workday; $0=$ day off $)$ & $-5.161(-6.051$ to -4.271$)$ & $<0.001$ & $-1.934(-2.312$ to -1.556$)$ & $<0.001$ \\
\hline
\end{tabular}

The dependent variables in the linear mixed effects regression models were $\mathrm{MVPA}_{1} \mathrm{~min}$ and $\mathrm{VPA}_{1 \mathrm{~min}}(\mathrm{~min} /$ day) as continuous variables. MVPA $_{1 \mathrm{~min}}$, moderate-to-vigorous physical activity ( $\geq 3$ metabolic equivalents (METs)) calculated from single 1 min bouts throughout the measurement period.

$\mathrm{VPA}_{1 \mathrm{~min}}$, vigorous physical activity ( $\geq 6 \mathrm{METs}$ ) calculated from single 1 min bouts throughout the measurement period.

$67.3 \%$ when $\geq 10$ min bouts were included in the calculation and was $88.6 \%, 95 \%$ CI $86.8 \%$ to $90.1 \%$ when $\geq 1$ min bouts were included) and lowest among obese women $(10.3 \%, 95 \%$ CI $8.4 \%$ to $12.4 \%$, and $23.0 \%, 95 \%$ CI $20.3 \%$ to $25.8 \%$, respectively).

\section{DISCUSSION}

We found that the amount of physical activity decreases with increasing age and increasing BMI for both genders, but shows a deeper decline among women. The amount of VPA was particularly low among older (51-65 years), and obese and overweight women. Men had more physical activity than women; physical activity was more common during days off than during workdays, especially among men. The hourly distribution of physical activity clearly differed between workdays and days off. During workdays, physical activity was most common early in the morning and right after working hours, whereas physical activity was distributed more evenly throughout the day during days off. In addition, the proportion of participants fulfilling the aerobic physical activity recommendations decreased with increasing BMI and was lower for women than for men. Approximately one-third of the obese men and onetenth of obese women fulfilled the aerobic physical activity recommendations.

\section{Strengths and weaknesses of the study}

Our study has several strengths. First, our study sample was very large and included a wide range of non-manual and manual labour employees although we did not have individual self-reported information on job titles available for the analysis in our data mining/register type

Table 5 Probability of having a bout of moderate-to-vigorous (MVPA) or vigorous (VPA) physical activity (per measurement day) lasting continuously for $\geq 10 \mathrm{~min}$

\begin{tabular}{|c|c|c|c|c|}
\hline & \multicolumn{2}{|l|}{ MVPA } & \multicolumn{2}{|l|}{ VPA } \\
\hline & $\begin{array}{l}\text { Unstandardised regression } \\
\text { coefficient }(95 \% \mathrm{Cl})\end{array}$ & p Value & $\begin{array}{l}\text { Unstandardised regression } \\
\text { coefficient }(95 \% \mathrm{Cl})\end{array}$ & p Value \\
\hline \multicolumn{5}{|l|}{ Simple models } \\
\hline Age $(18$ yrs=0) & $-0.040(-0.043$ to -0.036$)$ & $<0.001$ & $-0.047(-0.052$ to -0.042$)$ & $<0.001$ \\
\hline Gender ( $1=$ men; $0=$ women $)$ & $0.948(0.881$ to 1.016$)$ & $<0.001$ & 1.263 (1.163 to 1.363$)$ & $<0.001$ \\
\hline Body mass index $\left(18.5 \mathrm{~kg} / \mathrm{m}^{2}=0\right)$ & $-0.139(-0.148$ to -0.130$)$ & $<0.001$ & $-0.186(-0.202$ to -0.171$)$ & $<0.001$ \\
\hline Type of day ( $1=$ workday; $0=$ day off) & $-0.189(-0.242$ to -0.135$)$ & $<0.001$ & $-0.244(-0.322$ to -0.167$)$ & $<0.001$ \\
\hline \multicolumn{5}{|l|}{ Interaction models } \\
\hline Age $(18$ yrs $=0)$ & $-0.023(-0.031$ to -0.014$)$ & $<0.001$ & $-0.032(-0.043$ to -0.021$)$ & $<0.001$ \\
\hline Gender ( $1=$ men; $0=$ women $)$ & $-0.157(-0.400$ to 0.086$)$ & 0.21 & $-0.764(-1.100$ to -0.427$)$ & $<0.001$ \\
\hline Body mass index $\left(18.5 \mathrm{~kg} / \mathrm{m}^{2}=0\right)$ & $-0.078(-0.107$ to -0.050$)$ & $<0.001$ & $-0.126(-0.170$ to -0.081$)$ & $<0.001$ \\
\hline Type of day ( $1=$ workday; $0=$ day off) & $0.135(-0.049$ to 0.319$)$ & 0.15 & $0.004(-0.231$ to 0.240$)$ & 0.97 \\
\hline Age*body mass index & $-0.003(-0.004$ to -0.002$)$ & $<0.001$ & $-0.006(-0.008$ to -0.004$)$ & $<0.001$ \\
\hline Gender*age & $0.030(0.022$ to 0.037$)$ & $<0.001$ & $0.058(0.047$ to 0.068$)$ & $<0.001$ \\
\hline Gender*body mass index & $0.068(0.050$ to 0.086$)$ & $<0.001$ & $0.116(0.085$ to 0.147$)$ & $<0.001$ \\
\hline Type of day*age & $-0.009(-0.015$ to -0.004$)$ & 0.001 & $-0.016(-0.024$ to -0.008$)$ & $<0.001$ \\
\hline Type of day*gender & $-0.349(-0.460$ to -0.238$)$ & $<0.001$ & $-0.188(-0.364$ to -0.013$)$ & 0.035 \\
\hline Type of day*body mass index & $0.012(-0.003$ to 0.027$)$ & 0.12 & $0.040(0.013$ to 0.066$)$ & 0.003 \\
\hline \multicolumn{5}{|c|}{$\begin{array}{l}\text { MVPA ( } \geq 3 \text { metabolic equivalents (METs)); VPA ( } \geq 6 \text { METs). } \\
\text { The results are from the generalised linear mixed effects regression models in which the dependent variables are binary outcomes } \\
\text { (participant did or did not have a bout of moderate-to-vigorous or vigorous physical activity lasting } \geq 10 \text { min) and each participant is } \\
\text { incorporated as a random effect. In the simple models, the fixed effects are age, gender, body mass index and type of day. In the interaction } \\
\text { models, the fixed effects are aqe, gender, body mass index, type of day and all of their possible two-way interactions. }\end{array}$} \\
\hline
\end{tabular}



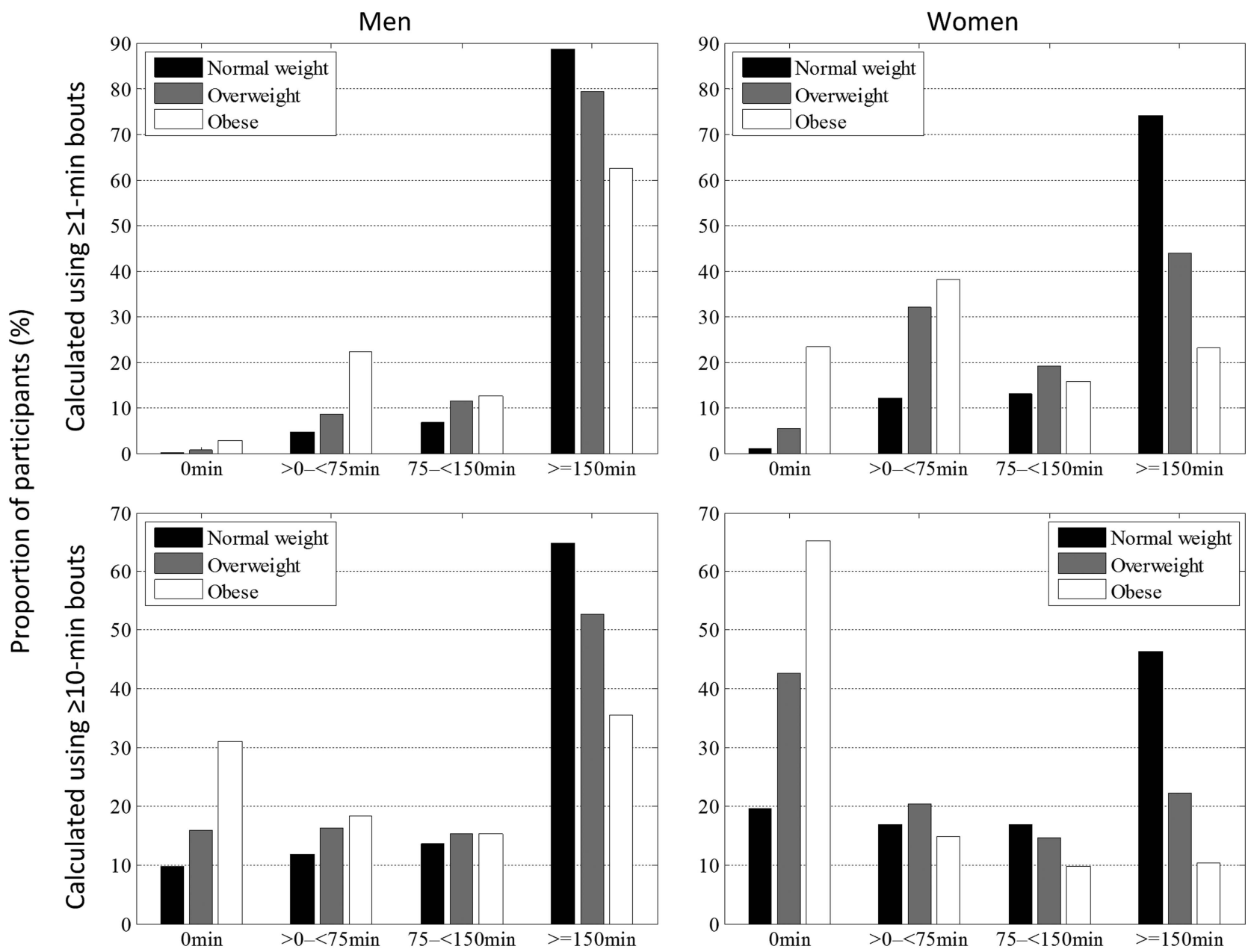

Figure 5 The proportion of participants fulfilling the aerobic physical activity recommendation (moderate-intensity physical activity for at least $150 \mathrm{~min} /$ week, vigorous physical activity at least $75 \mathrm{~min} /$ week, or a combination of these) based on gender and weight status. Normal weight $=18.5$ to $<25 \mathrm{~kg} / \mathrm{m}^{2}$; overweight $=25$ to $<30 \mathrm{~kg} / \mathrm{m}^{2}$; obese $=30-40 \mathrm{~kg} / \mathrm{m}^{2}$. Note the different scales between the upper and lower figures.

study. Second, we used a novel ambulatory beat-to-beat R-R interval-based method to assess the intensity of physical activity. This method has been shown to provide more accurate estimates of the intensity of physical activity than HR information. ${ }^{20} 29$ Third, we had a strict criteria for the inclusion of recording days (eg, measurement error $<15 \%$ and recording break $<30 \mathrm{~min}$ ); thus, our recordings had a good coverage of typical workdays and days off. Nonetheless, our study also has some weaknesses. Most of the participants were apparently healthy, but some participants with chronic diseases and/or medications that did not severely affect HR were also included in the sample of employees. We did not adjust for these conditions in the analysis since this information was not available for the analysis in our data mining/register type study. In addition, the study sample was not a random sample from the population, but a 'real-life' clinical sample of employees who participated in the preventive occupational healthcare activities. This can be considered as either a strength or a weakness depending on the perspective. Our method for assessing physical activity can differentiate between the intensities of physical activity MET by MET, but to simplify our presentations, we used cut-off points of $\geq 3$ and $\geq 6$ METs to describe MVPA and VPA, respectively, as these are used in the physical activity recommendations. ${ }^{12}$ The durations of our recordings were from 2 to 6 days and on the basis of these recordings, the amount of weekly physical activity was estimated in order to determine the proportion of participants who fulfil the aerobic physical activity recommendations. To accurately assess individual long-term physical activity levels, a longer recording is more valid than the duration used in our study. ${ }^{30}$ Our recordings usually covered some typical workdays and days off, as our aim was to obtain recordings covering most of the day without artefacts. To achieve this goal, stick-on electrodes with wires were used for the collection of R-R interval data but in some individuals, the electrodes cause skin irritation and this makes it difficult to get long recordings.

\section{Findings in relation to other studies}

The majority of previous studies including large study populations used accelerometers or pedometers for the 
Table 6 Proportion of participants fulfilling the aerobic physical activity recommendation* based on gender and weight status

$\begin{array}{ll}\text { Men } & \text { Women } \\ \text { Per cent }(95 \% \mathrm{Cl}) & \text { Per cent }(95 \% \mathrm{Cl})\end{array}$

$\mathrm{MVPA}_{1 \mathrm{~min}}$

All

80.0 (78.8 to 81.2$) \quad 56.1$ (54.7 to 57.4$)$

Normal weight

Overweight

Obese

MVPA $_{10 \mathrm{~min}}$

All

88.6 (86.8 to 90.1$) \quad 74.1$ (72.4 to 75.7$)$

79.4 (77.6 to 81.1$) \quad 43.8$ (41.3 to 46.2$)$

62.5 (58.7 to 66.2$) \quad 23.0$ (20.3 to 25.8$)$

54.3 (52.8 to 55.8$) \quad 32.8$ (31.6 to 34.1$)$

Normal weight 64.9 (62.4 to 67.3$) \quad 46.5$ (44.6 to 48.3 )

Overweight $\quad 52.7$ (50.5 to 54.9$) \quad 22.1$ (20.1 to 24.2)

Obese $\quad 35.5$ (31.9 to 39.3) $\quad 10.3$ (8.4 to 12.4)

*Moderate-intensity aerobic physical activity at least $150 \mathrm{~min} /$ week, vigorous physical activity at least $75 \mathrm{~min} /$ week, or a combination of these (for details of calculation, see methods).

Normal weight $=18.5$ to $<25 \mathrm{~kg} / \mathrm{m}^{2}$; overweight $=25$ to $<30 \mathrm{~kg} / \mathrm{m}^{2}$; obese $=30-40 \mathrm{~kg} / \mathrm{m}^{2}$

$\mathrm{MVPA}_{1 \mathrm{~min}}$, moderate-to-vigorous physical activity ( $\geq 3$ metabolic equivalents (METs)) calculated from single $1 \mathrm{~min}$ bouts throughout the measurement period.

MVPA10 min, moderate-to-vigorous physical activity ( $\geq 3$ METs) calculated from bouts of physical activity lasting continuously for $\geq 10 \mathrm{~min}$.

objective assessment of physical activity. These methods provide rough estimates of the intensity of physical activity. We used beat-to-beat R-R interval data which allows for more accurate estimations of the intensity of physical activity, but it also has limitations when comparing our results to previous results. The age-associated and BMI-associated declines in the amount of physical activity observed in our study are in agreement with the results of the studies using accelerometers. ${ }^{14} 1718{ }^{31} \mathrm{In}$ our study, the amount of VPA was very low, especially among older women, and overweight and obese women; similar results have been reported in previous studies that used accelerometers. ${ }^{14} 1731$ Our results showing the clear difference between workdays and days off in the hourly distribution of physical activity are in accordance with previous studies. ${ }^{18}$ In addition, we observed that the proportions of overweight and obese participants fulfilling the aerobic physical activity recommendations are lower than the proportion of normal weight participants. Previous studies obtained similar results-showing that among obese individuals, especially, the amount of VPA is low compared with the current recommendation. ${ }^{14} 1618$ Previous questionnaire-based studies in Finland have reported that approximately one-quarter ${ }^{32}$ to one-half ${ }^{33}$ of the working-age adults (men and women) fulfil the current aerobic physical activity recommendation. Our objectively measured results (men 54\%, women 33\%) covering work-related and leisure physical activities are roughly in line with these results.

Overall, most of the associations in our study are similar to previous population-based studies that used accelerometers. However, our method measures cardiorespiratory loading more directly than the methods based on motion sensors. The amount of physical activity calculated from the bouts lasting $\geq 10 \mathrm{~min}$ should be used when determining who meets the current physical activity recommendations. ${ }^{3}$ We calculated the amount of MVPA and VPA in two different ways that reflect different aspects of physical activity. The amount of physical activity calculated from single $1 \mathrm{~min}$ bouts throughout the measurement period may be considered to reflect daily activities, rather than fitness-enhancing exercise, as this method also takes into account very short bouts of physical activity, such as climbing stairs. Interestingly, the proportion of participants fulfilling the aerobic physical activity recommendation is doubled when shorter bouts are included in the calculation (table 6).

\section{Meaning of the study: implications for clinicians and policymakers}

Increasing physical activity and reducing obesity are both important targets for improving overall population health as obesity as well as low physical activity are predictors of mortality. ${ }^{34}$ According to our study, approximately one-third of Finnish working-age women and half of working-age men meet the current recommendations for aerobic physical activity. The proportion is especially low among overweight and obese women and obese men. On the basis of this and our other observations, the amount of physical activity, especially the amount of VPA, seems to be very low among overweight and obese individuals, particularly women. As our study is crosssectional in nature, it does not show the direction of causality between physical activity and obesity. However, this evidence shows the vicious cycle between obesity and physical inactivity. ${ }^{35}$ The low number of obese individuals meeting the recommendations and their low starting level (with regard to total amount, duration and intensity) should be taken into account when implementing interventions for increasing physical activity. For obese individuals, the amount of MPA or perhaps low-intensity activity should be increased first. Among obese individuals, objectively measured physical activity seems to be low, during leisure and at work. Thus, leisure hours and working hours need to be considered when recording the activity interventions. Overall, the documentation of physical activity levels as a part of routine healthcare check should be improved. ${ }^{36}$

\section{Unanswered questions and future research}

In the light of our findings, long-term controlled intervention studies are needed to show whether MPA or VPA as the main component of intervention programmes has a better benefit-risk balance for obese individuals in terms of adherence, weight control, morbidity and mortality. Also, more detailed research is needed on whether short bouts of physical activity lead to long-term health benefits comparable to longer bouts at the 
disease-outcome level. Accurate methods of monitoring physical activity that cover cardiorespiratory loading are also needed to carry out large-scale studies on these topics and to analyse whether specific types of shortterm activity provide health benefits. Notably, some physical activity is under the intensity level of 3 METs, which was not taken into account in our current analysis. Long-term intervention studies on the effects of physical activity of (very) low intensity on disease outcomes are lacking.

Acknowledgements The authors thank Firstbeat Technologies Ltd for providing the data for analysis. They also thank Kaisa Hämäläinen, Jaakko Kotisaari and Tero Myllymäki, Firstbeat Technologies Ltd, for their assistance in the first stages of data mining and their valuable comments on the methods section of this paper.

Contributors All authors participated in planning the study design and statistical analyses, revision of the manuscript and approved the final version. SM and UMK (guarantor) drafted the manuscript. EH and JP carried out the analysis.

Funding This work was partially supported by the SalWe Research Program for Mind and Body (Tekes - the Finnish Funding Agency for Technology and Innovation grant 1104/10).

Competing interests All authors have completed the ICMJE uniform disclosure form at http://www.icmje.org/coi_disclosure .pdf and declare: all authors had financial support from Tekes (The Finnish Funding Agency for Innovation) for the submitted work; EH, JP and IK report research grant from Firstbeat Technologies Ltd, during the conduct of the study, and they also report other research grant from Firstbeat Technologies Ltd, outside the submitted work; and IK is a co-founder in PulseOn Ltd, which is a company developing optical heart rate monitoring technology, http://www.pulseon.com

Ethical approval This study was approved by the Ethics Committee of Tampere University Hospital (Reference No R13160).

Provenance and peer review Not commissioned; externally peer reviewed.

Data sharing statement No additional data are available.

Open Access This is an Open Access article distributed in accordance with the Creative Commons Attribution Non Commercial (CC BY-NC 4.0) license, which permits others to distribute, remix, adapt, build upon this work noncommercially, and license their derivative works on different terms, provided the original work is properly cited and the use is non-commercial. See: http:// creativecommons.org/licenses/by-nc/4.0/

\section{REFERENCES}

1. Pan XR, Li GW, Hu YH, et al. Effects of diet and exercise in preventing NIDDM in people with impaired glucose tolerance. The Da Qing IGT and Diabetes Study. Diabetes Care 1997;20:537-44.

2. Ohkawara K, Tanaka S, Miyachi M, et al. A dose-response relation between aerobic exercise and visceral fat reduction: systematic review of clinical trials. Int J Obes 2007;31:1786-97.

3. Physical Activity Guidelines Advisory Committee. Physical Activity Guidelines Advisory Committee report, 2008. Washington, DC: U.S. Department of Health and Human Services, 2008.

4. Waller K, Kaprio J, Lehtovirta M, et al. Leisure-time physical activity and type 2 diabetes during a 28 -year follow-up in twins. Diabetologia 2010;53:2531-7.

5. Kujala UM, Mäkinen V-P, Heinonen I, et al. Long-term leisure-time physical activity and serum metabolome. Circulation 2013;127: 340-8.

6. Sattelmair J, Pertman J, Ding EL, et al. Dose response between physical activity and risk of coronary heart disease. A meta-analysis. Circulation 2011;124:789-95.

7. Li J, Siegrist J. Physical activity and risk of cardiovascular diseasea meta-analysis of prospective cohort studies. Int J Environ Res Public Health 2012;9:391-407.
8. Reiner M, Niermann C, Jekauc D, et al. Long-term health benefits of physical activity - a systematic review of longitudinal studies. BMC Public Health 2013;13:813.

9. Mammen G, Faulkner G. Physical activity and the prevention of depression. A systematic review of prospective studies. Am J Prev Med 2013;45:649-57.

10. Samitz G, Egger M, Zwahlen M. Domains of physical activity and all-cause mortality: systematic review and dose-response meta-analysis of cohort studies. Int J Epidemiol 2011;40: 1382-400.

11. World Health Organization. Global recommendations on physical activity for health. Geneva: World Health Organization; 2010.

12. Garber CE, Blissmer B, Deschenes MR, et al. American College of Sports Medicine Position Stand. Quantity and quality of exercise for developing and maintaining cardiorespiratory, musculoskeletal, and neuromotor fitness in apparently healthy adults: guidance for prescribing exercise. Med Sci Sports Exerc 2011:43:1334-59.

13. Butte NF, Ekelund U, Westerterp KR. Assessing physical activity using wearable monitors: measures of physical activity. Med Sci Sports Exerc 2012;44:S5-12.

14. Archer E, Hand GA, Hébert JR, et al. Validation of a novel protoco for calculating estimated energy requirements and average daily physical activity ratio for the US population: 2005-2006. Mayo Clin Proc 2013;88:1398-407.

15. Westerterp KR. Assessment of physical activity: a critical appraisal. Eur J Appl Physiol 2009;105:823-8.

16. Hagströmer M, Oja $P$, Sjöström M. Physical activity and inactivity in an adult population assessed by accelerometry. Med Sci Sports Exerc 2007;39:1502-8.

17. Tucker JM, Welk GJ, Beyler NK. Physical activity in U.S. adults. Compliance with the Physical Activity Guidelines for Americans. Am J Prev Med 2011;40:454-61.

18. Hansen $\mathrm{BH}$, Holme I, Anderssen SA, et al. Patterns of objectively measured physical activity in normal weight, overweight, and obese individuals (20-85 years): a cross-sectional study. PLOS ONE 2013;8:e53044.

19. Achten J, Jeukendrup AE. Heart rate monitoring. Applications and limitations. Sports Med 2003;33:517-38.

20. Smolander J, Ajoviita M, Juuti T, et al. Estimating oxygen consumption from heart rate and heart rate variability without individual calibration. Clin Physiol Funct Imaging 2011;31: 266-71.

21. Teisala T, Mutikainen S, Tolvanen A, et al. Associations of physical activity, fitness, and body composition with heart rate variability-based indicators of stress and recovery on workdays: a cross-sectional study. J Occup Med Toxicol 2014;9:16.

22. Firstbeat Technologies Ltd. EPOC based training effect assessment [White paper]. Published Sep 2005, updated March 2012. http:// www.firstbeat.com/userData/firstbeat/download/white paper training_effect.pdf

23. Ross RM, Jackson AS. Exercise concepts, calculations, and computer applications. Carmel, Indiana, USA: Benchmark Press; 1990.

24. Jones NL. Clinical exercise testing. 3rd edn. Philadelphia: W.B. Saunders; 1988

25. Jackson AS, Blair SN, Mahar MT, et al. Prediction of functional aerobic capacity without exercise testing. Med Sci Sports Exerc 1990;22:863-70.

26. Saalasti S. Neural networks for heart rate time series analysis [dissertation]. Jyväskylä, Finland: University of Jyväskylä; 2003. https://jyx.jyu.fi/dspace/bitstream/handle/123456789/13267/ 951391707X.pdf?sequence $=1$

27. Kettunen J, Saalasti S, inventors; Firstbeat Technologies Ltd, assignee. Procedure for deriving reliable information on respiratory activity from heart period measurement. United States patent US 7,460,901 B2. 2 Dec 2008. http://worldwide.espacenet.com/ publicationDetails/originalDocument?CC=US\&NR=7460901B2\& $\mathrm{KC}=\mathrm{B} 2 \& \mathrm{FT}=\mathrm{D} \& N D=4 \&$ date $=20081202 \& \mathrm{DB}=\mathrm{EPODOC} \&$ locale $=$ fi $\mathrm{F}$

28. Kettunen J, Saalasti S, inventors; Firstbeat Technologies Ltd, assignee. Procedure for detection of stress by segmentation and analyzing heart beat signal. United States patent US 7,330,752 B2. 12 Feb 2008. http://worldwide.espacenet.com/publicationDetails/ originalDocument?FT=D\&date $=20080212 \& D B=E P O D O C \& l o c a l e=f i$ $\mathrm{FI} \& \mathrm{CC}=\mathrm{US} \& \mathrm{NR}=7330752 \mathrm{~B} 2 \& \mathrm{KC}=\mathrm{B} 2 \& \mathrm{ND}=4$

29. Firstbeat Technologies Ltd. VO2 estimation method based on heart rate measurement [white paper]. Published Feb 2005, updated March 2012. http://www.firstbeat.com/userData/firstbeat/download/ white_paper_vo2_estimation.pdf 
30. Kang M, Bassett DR, Barreira TV, et al. How many days are enough? A study of 365 days of pedometer monitoring. Res $Q$ Exerc Sport 2009;80:445-53.

31. Troiano RP, Berrigan D, Dodd KW, et al. Physical activity in the United States measured by accelerometer. Med Sci Sports Exerc 2008;40:181-8.

32. Husu $P$, Suni J, Vähä-Ypyä $H$, et al. The level of physical activity and sedentary behaviour in Finnish adults. Suomen Lääkärilehti 2014;69:1860-6. (in Finnish; abstract available in English).

33. Helakorpi S, Laitalainen E, Uutela A. Health behaviour and health among the Finnish adult population, spring 2009. National Institute for Health and Welfare (THL), Report 7/2010. (in Finnish; abstract, tables and figures available in English).

34. Hu FB, Willett WC, Li T, et al. Adiposity as compared with physical activity in predicting mortality among women. $N$ Engl $\mathrm{J} \mathrm{Med}$ 2004;351:2694-703.

35. Pietiläinen $\mathrm{KH}$, Kaprio J, Borg $\mathrm{P}$, et al. Physical inactivity and obesity: a vicious circle. Obesity 2008;16:409-14.

36. Strath SJ, Kaminsky LA, Ainsworth BE, et al. Guide to the assessment of physical activity: clinical and research applications: a scientific statement from the American Heart Association. Circulation 2013;128:2259-79. 